\title{
Research on the design of travel aids for the elderly with partial disability of lower limbs
}

\author{
Zhu Tian Yang ${ }^{1, a}$, Wang Hui Min²,b ${ }^{2}$ Zhou Jun Liang ${ }^{3, c}$ \\ ${ }^{1}$ School of Mechanical and Electrical Engineering, Beijing University of Chemical Technology, Beijing, China \\ ${ }^{2}$ School of Mechanical and Electrical Engineering, Beijing University of Chemical Technology, Beijing, China \\ ${ }^{3}$ School of Mechanical and Electrical Engineering, Beijing University of Chemical Technology, Beijing, China
}

\begin{abstract}
As the population continues to age, the daily lives of those with disabled lower limbs have gradually become an unavoidable social welfare problem. Based on an investigation and analysis into the daily routines of the elderly with partial disability in their lower limbs, the product design experiment is proposed to solve any mobility difficulties in the elderly with partial disability in their lower limbs to provide practical help that can ensure their independence and social contact. Based on the literature research and market comparison, According to the assessment criteria for the Instrumental Activity of Daily Living Scale (IADL), the physiological functions and user behaviors of this elderly population were investigated, and the actual needs for outdoor walking were analyzed. The idea of focusing on auxiliary tools for the elderly with lower limb disability was proposed, and a tool to aid in short-distance travel was designed for this target group to improve their IADL travel index and optimize their mobility.
\end{abstract}

\section{Introduction}

The aging of the population, mainly involving the increasingly prominent aging tendency and the increasing proportion of the elderly year by year, is a common challenge of social development in today's world. The data predicts that the number of the elderly disabled and semidisabled in China may surge to 42.5 million in 2020, accounting for about $18.3 \%$ of the total elderly population. Therefore, the daily life of the elderly disabled and semidisabled has become a key concern of national social security [1]. Currently, the degree of physical disability of the elderly can be evaluated according to the Instrumental Activity of Daily Living Scale (IADL), which includes 8 items, including riding, shopping, doing housework, washing, cooking, making a call, managing wealth and taking drugs, all of which shall be finished by themselves. It can be used to assess the quality of the elderly's daily life from such perspectives as the abilities to travel, live, think, etc.

Long-term partial disability of lower limbs will physiologically lead to muscle atrophy, the spread of physical disability range, the decrease of immunity caused by lack of exercise, and the delay of movement, thinking and perception system; it may easily lead to mental diseases such as senile depression, senile anxiety disorder, empty nest syndrome and senile dementia due to longterm staying at home caused by mobility inconvenience and lack of basic communication with the outside world, which would endanger physical and mental health [2]. However, using travel means of transport can meet the basic travel needs of the elderly with partial disability of lower limbs, facilitate daily social interaction, and improve the quality of life, which is beneficial for their physical and mental health. According to researches, sports rehabilitation treatment and mental intervention treatment could help the elderly partially disabled relieve the degree of limb lesion, improve their mental status and finally contributes to certain enhancement of their physiological function [3]. Compared with the elderly completely disabled, the elderly partially disabled have more robust ability to travel, and their physical functions can meet simple and short-distance travel activities. At present, the common travel aids for the elderly in the market can be generally divided into open and closed types according to the appearance structure [4]. The representative products of the open type include multifunctional wheelchairs, tricycles, and electric mobility scooters. These products are flexible and convenient for parking and storage, but they are easily affected by natural environment and have weak protection for users. The appearance of the products of the closed type is mostly automobile-shaped, which makes storage convenient and more comfortable. However, it is difficult for elderly users to operate, and the management of travel and parking is difficult [5]. The existing travel aids for the elderly are polarized, mainly for two types of elderly users who can take care of themselves completely and lose their mobility, but not for the elderly who are partially incapacitated [6].

azhuty@mail.buct.edu.cn

bwanghyldy@163.com, ${ }^{\mathrm{c}}$ zhouj1@mail.buct.edu.cn 


\section{Physiological Characteristics and Behavioral Analysis of the Elderly with Partial Disability in the Lower Limbs}

\subsection{Physiological Characteristics of the Elderly with Partial Disability in the Lower Limbs}

The Product was designed based on the travelling demand of the elderly with partial disability of lower limbs. First of all, the etiologies and pathologies of the elderly with partial disability of lower limbs were analyzed, so that the Product could be designed by considering their actual physical conditions based on the ergonomic principle. From the anatomical point of view, the muscles around the knee joint are weak, and the lever formed by the upper and lower bones bears $86 \%$ of the weight of the human body [7] . However, the elderly have osteoporosis in different degrees, which can be embodied by the thinner internal surface of long and flat bones due to bone absorption, and the problem of "internal insufficient bone and external sufficient bone" by the slow formation of new bone external surface. The above leads to a higher bone brittleness which results in higher fracture risk during exercise [8]. The degenerative changes of leg joints of the elderly with partial disability of lower limbs are more obvious, including articular cartilages of knee and ankle joints, sclerotin, synovium, and synovia along with the increase of age, causing degenerative arthritis (Figure 1). The common pathologies of the elderly with partial disability of lower limbs include articular cartilage injury, synovia's loss and viscosity increase, decreased muscle gross, muscle strength and muscle tension, lower muscle cell viability caused by waste muscular atrophy, etc.. All these symptoms will increase the walking resistance of the elderly with partial disability of lower limbs, which, as a result, leads to higher wear of legs and joints and the lack of physical strength during exercises and finally restricts their activities.

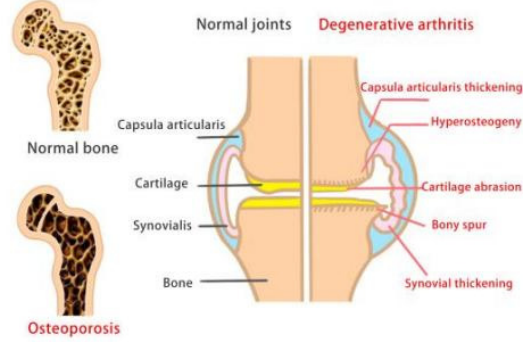

Figure 1. Comparison of bone and joint structure in the elderly

\subsection{Behavioral Analysis of the Elderly with Partial Disability in the Lower Limbs}

The activities of daily living of the elderly are affected by the physiological degenerative diseases. For the elderly with partial disability of lower limbs, most of their daily outings are for shopping, leisure and physical exercise, and their activities are mostly distributed in supermarkets and parks around the community [9]. According to the survey, the travel distance distribution of the elderly with such disability is drawn, as shown in Figure 1. It can be seen from the table that the daily travel distance of the elderly with partial disability of lower limbs is about $3 \mathrm{~km}$, mainly short-distance travel. As far as the travel frequency is concerned, the data show that about $90 \%$ of the elderly with partial disability of lower limbs are willing to choose to go out daily, and only about $10 \%$ go out less because of physical illness, psychological emotion and other reasons [10]. It can be seen that the elderly with partial disability of lower limbs have a strong willingness to travel and are willing to communicate with the outside world, which requires the help of travel aids to complete their daily social activities.

Table1. Travel distribution of disabled elderly in lower extremity

\begin{tabular}{|c|c|c|c|c|}
\hline Distance & $\leq 1 \mathrm{Km}$ & $1-2 \mathrm{Km}$ & $2-3 \mathrm{Km}$ & $\geq 3 \mathrm{Km}$ \\
\hline Activities & $\begin{array}{l}\text { Go downstairs for } \\
\text { emptying the } \\
\text { garbage } \\
\text { Take drinking } \\
\text { water } \\
\text { Take things from } \\
\text { storeroom }\end{array}$ & $\begin{array}{c}\text { Communicate with } \\
\text { neighbors } \\
\text { Exercise in } \\
\text { community } \\
\text { Take a walk }\end{array}$ & $\begin{array}{l}\text { Parks around } \\
\text { community } \\
\text { Fitness and } \\
\text { recreation } \\
\text { Shopping and } \\
\text { purchasing }\end{array}$ & $\begin{array}{l}\text { Visit friends } \\
\text { Pick up children } \\
\text { Others }\end{array}$ \\
\hline Safety degree & Safe & Relatively safe & $\begin{array}{l}\text { Potential safety } \\
\text { hazards available }\end{array}$ & $\begin{array}{l}\text { Relatively } \\
\text { dangerous }\end{array}$ \\
\hline
\end{tabular}

The design principle of the mobility aids for the elderly with partial disability of lower limbs were summarized by analyzing the demand of the targeted costumers. The Product is targeted at the elderly with partial disability of lower limbs assessed by the Instrumental Activity of Daily Living Scale (IADL), in order to help solve their travelling and surrounding service problems. IADL mainly assesses the life quality of the elderly based on their daily behaviors and cognitive abilities. After being surveyed based on the original assessment mode, the Product has been improved by taking targeted customers' demands into consideration. The items were divided again by focusing on the actual functions of the Product so as to better comply with the use effect of the Product and form a new experiment assessment table (Table 2). The Product can help the elderly with partial disability of lower limbs, who use other similar products with 2 to 3 points through assessment, to reach the assessment standard of 0 to 1 points and ultimately improve their life quality. 
Table2. Product test scale based on IADL assessment criteria

\begin{tabular}{|c|c|c|c|c|c|}
\hline A. Riding & B. Shopping & C.Travelling & $\begin{array}{l}\text { D. Carrying } \\
\text { Heavy Objects }\end{array}$ & $\begin{array}{l}\text { E. Arrangement } \\
\text { and Storage }\end{array}$ & $\begin{array}{l}\text { F. Stairs- } \\
\text { climbing }\end{array}$ \\
\hline $\begin{array}{c}\text { 1. Do it } \\
\text { normally ( } 0 \\
\text { point) } \\
\end{array}$ & $\begin{array}{l}\text { 1. Do it normally ( } 0 \\
\text { point) }\end{array}$ & $\begin{array}{c}\text { 1. Do it } \\
\text { normally (0 } \\
\text { point) }\end{array}$ & $\begin{array}{l}\text { 1. Do it normally } \\
\text { ( } 0 \text { point })\end{array}$ & $\begin{array}{l}\text { 1. Do it normally } \\
(0 \text { point })\end{array}$ & $\begin{array}{c}\text { 1. Do it } \\
\text { normally (0 } \\
\text { point) }\end{array}$ \\
\hline $\begin{array}{l}\text { 2. Able to } \\
\text { complete with } \\
\text { difficulty (1 } \\
\text { point) }\end{array}$ & $\begin{array}{l}\text { 2. Able to complete } \\
\text { with difficulty (1 } \\
\text { point) }\end{array}$ & $\begin{array}{l}\text { 2. Able to } \\
\text { complete with } \\
\text { difficulty (1 } \\
\text { point) }\end{array}$ & $\begin{array}{c}\text { 2. Able to } \\
\text { complete with } \\
\text { difficulty (1 point) }\end{array}$ & $\begin{array}{l}\text { 2. Able to } \\
\text { complete with } \\
\text { difficulty (1 } \\
\text { point) }\end{array}$ & $\begin{array}{l}\text { 2. Able to } \\
\text { complete with } \\
\text { difficulty (1 } \\
\text { point) }\end{array}$ \\
\hline $\begin{array}{l}\text { 3. Help required } \\
\text { (2 points) }\end{array}$ & $\begin{array}{l}\text { 3. Help required ( } 2 \\
\text { points) }\end{array}$ & $\begin{array}{l}\text { 3. Help required } \\
\text { (2 points) }\end{array}$ & $\begin{array}{l}\text { 3. Help required ( } 2 \\
\text { points) }\end{array}$ & $\begin{array}{l}\text { 3. Help required } \\
\text { (2 points) }\end{array}$ & $\begin{array}{l}\text { 3. Help required } \\
\text { (2 points) }\end{array}$ \\
\hline $\begin{array}{l}\text { 4. Rely on others } \\
\text { totally ( } 3 \text { points) }\end{array}$ & $\begin{array}{l}\text { 4. Rely on others } \\
\text { totally ( } 3 \text { points) }\end{array}$ & $\begin{array}{l}\text { 4. Rely on } \\
\text { others totally ( } 3 \\
\text { points) }\end{array}$ & $\begin{array}{l}\text { 4. Rely on others } \\
\text { totally ( } 3 \text { points) }\end{array}$ & $\begin{array}{l}\text { 4. Rely on others } \\
\text { totally ( } 3 \text { points) }\end{array}$ & $\begin{array}{l}\text { 4. Rely on } \\
\text { others totally ( } 3 \\
\text { points) }\end{array}$ \\
\hline
\end{tabular}

The orientations to design travel means of transport for the elderly with partial disability of lower limbs mainly include two types, of which, the first one is the new energy battery-powered electric wheelchair with a relatively slow speed, which belongs to a kind of medical instrument. The second one is the fully enclosed mobility car, the capacity of which is higher than that of wheelchair. Furthermore, less affected by environmental factors, it is popular among a majority of elderly but it is hard to control [11]. Comparatively speaking, the Product is designed by integrating the strengths of both of the above, satisfying the requirements for low learning cost and high usage rate and complying with the ergonomic principle and customers' physical demand and in particular, the actual demand of the elderly with partial disability of lower limbs. Firstly, from the perspective of product function, the product should meet the needs of short-distance travel, shopping and entertainment for the elderly with partial disability of lower limbs, which can accommodate one person with certain storage function. Considering that the ability of the elderly to learn and accept new things is reduced, the complex functions of the product should be simplified and the operation difficulty should be reduced. Secondly, from the perspective of product appearance, considering the psychological factors that some of the elderly refuse to be labeled as "old people", we should optimize the product design, reduce the rigid inflection point and acute angle through smooth and round lines and harmonious and comfortable proportion, and give the product a light and energetic appearance, which is in line with the aesthetic preference of the elderly [12]. In the aspect of color matching, based on the suggestive effect of different colors on psychology in color psychology, colors that can soothe emotions and eliminate fatigue should be selected [13] . Finally, as far as the product structure is concerned, the body size design of the mobility scooter should be adapted to the average height and bone structure of the elderly in Asia, and the overall structure adopts foldable design, which is convenient to carry and store. Due to injuries such as knee joint, ankle joint and decreased muscle strength, the elderly with partial disability of lower limbs will have difficulties to a certain extent in the transition from sitting to standing [14]. Therefore, the auxiliary standing function should be added to the design of the handlebar of the mobility aids. With the increase of age, the hand muscle strength of the elderly will decrease by $16 \%-40 \%$, and the arm strength will decrease by about $50 \%$. The design of assistant standing at the handlebar can not only reduce the burden of standing for the elderly, but also slow down the muscle injury of upper limbs [15].

\section{Design and Application of Mobility Aides}

\subsection{Typical User Personas}

In order to further understand the user's needs, a target user is selected for in-depth interview, and a user personas is constructed based on his/her physiological characteristics, psychological characteristics, behavior habits and actual needs. The interviewee is Zhang Lan of 76 years old, who lives in the urban community with her husband. When she was young, she loved sports and was in good health. She was a volleyball player in school and often took physical exercises such as swimming and running. After retirement, the physical function gradually declined, and the physical strength dropped rapidly. Originally, she could ride a tricycle to pick up her granddaughter to and from school. Since suffering from rheumatoid arthritis and hyperosteogeny, her legs were obviously bent. Now she will feel sore and weak after walking for $1 \mathrm{~km}$, which makes it difficult to maintain long-distance travel. She is highly educated, willing to accept new things, in good mental state, and still have a high willingness to participate in community activities. At present, her means of transport is a human tricycle, which can meet the daily travel needs, but there are still some deficiencies such as bulky means of transport and excessive physical exertion.

Through comprehensive interview results and literature analysis, the basic information of typical user portraits is obtained, as shown in Figure 2: 


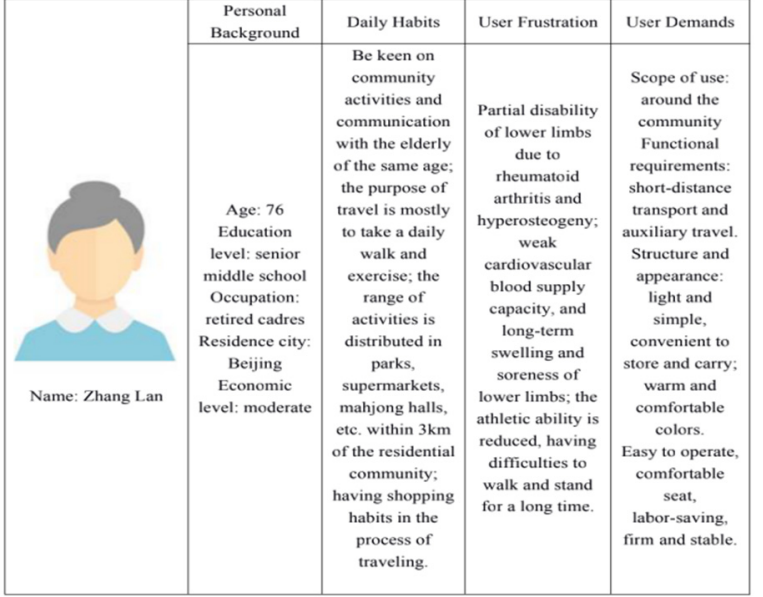

Figure 2. Typical target user portrait

\subsection{Design Scheme Effectiveness}

By analyzing the personas of the target user and summarizing the design principles, the design scheme is shown as below:

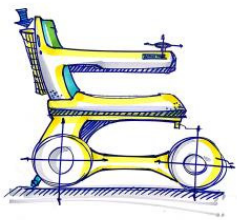

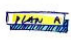

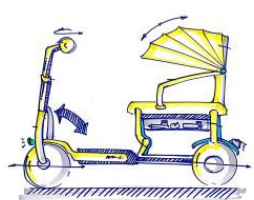

Pren Did

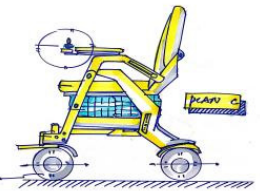

pean a
Figure 3. Design Schemes

The Scheme 1, as shown in Figure 3, plan A: The overall shape of the Product seems like a wheelchair. The backrest chair of the Product conforms to ergonomics, and the backrest and seat surface of the chair fit the curves of the back, waist and buttocks of the human body, thus improving the sedentary comfort. The chair's part contacting human body is made of soft and comfortable leather that is easy to clean and highly durable. The overall effect highlights the superior taste and texture, besides the economic and practical features. The wheel is made of natural rubber (NR) material, which assists body to buffer external shocks, and guarantee the car's driving performance. Tire shading is straight groove pattern, which can ensure operation stability, reduce rotation resistance and noise, facilitate drainage and avoids sideslip. On the back of the backrest seat, there is a net woven by 9 durable parachute cords, which is durable, easy to stretch and can store some objects. The weaknesses of the design: Direction is controlled using the front, back, left and right operating levers; low steering flexibility and uneasy operation.

The Scheme 2, as shown in Figure 3, plan B: The car body of the Product is made of ABS polymeric structural material which could enhance body strength, weaken impact influence and resist high heat and low temperature. The traditional handlebar design improves steering flexibility, and the hand-held brake simplifies braking operation to ensure driving safety. The scheme's seatback adopts the vinyl coating to enhance the UV filtering, and is put on a foldable dual-purpose vehicle shed. The closeable storage box is located under the seat to protect the stored articles. The scheme's tire pattern also adopts transverse groove pattern to increase the driving force, the traction force and the abrasive resistance. And the front and rear of the wheels are equipped with two kinds of lights to light up the front road and warn passers-by. Disadvantage of the design: The overall framework is large with the foldable part, which is not easy for carrying and storage.

The Scheme 3, as shown in Figure 3, plan B: The overall framework according to this scheme is similar with that in Scheme I but it is optimized in terms of steering control. With $360^{\circ}$ all-directional operating lever, it enjoys more intelligent and smoother steering direction. The seatback and chair seat, which are designed with anti-slip pattern on leather, become safer. Damping wheels are adopted, in which the damping springs are enclosed inside the frame, which has excellent dust-proof and antiwinding functions. The damping wheels adopt double tapered roller bearings, which can effectively prevent the scooter body from shaking during high-speed traction. The tire is made of butadiene styrene rubber (SBR), which is superior to natural rubber in terms of abrasive, heat resistance and ageing resistance. Disadvantage of the design: The overall shape makes it seem like a medical wheelchair, which does not consider the elderly's psychological resistance to such elements as "wheelchair", "unhealthy", "agedness", etc.

The final scheme sketch in Figure 6 was finally made on the basis of the three schemes above by analyzing and comparing their strengths and weaknesses. The Product should meet the short-distance traveling demand of the customers with partial disability of lower limbs, and assist them to travel in the residential area or nearby and even the surrounding field or street as specified in the Activity of Daily Living Scale (ADL) in terms of traveling. The portable electric scooter can help the elderly to save their energy and reduce joint wear while travelling and extend their travel distance on the basis of a favorable mental status. The car body of the Product is made of ABS polymeric structural material which could enhance body strength, weaken impact influence and resist high heat and low temperature. The backrest chair conforms to ergonomics, and the backrest and seat surface of the chair fit the curves of the back, waist and buttocks of the human body, thus improving the sedentary comfort. The traditional handlebar design improves steering flexibility, and the hand-held brake simplifies braking operation to ensure driving safety. The scheme's seatback adopts the vinyl coating to enhance the UV filtering, and is put on a foldable dual-purpose vehicle shed. The closeable storage box is located under the seat to protect the stored articles. Damping wheels are adopted, in which the damping springs are enclosed inside the frame, which has excellent dust-proof and anti-winding functions. The damping wheels adopt double tapered roller bearings, which can effectively prevent the scooter body from shaking during high-speed traction. The scheme's tire pattern also adopts transverse groove pattern to increase the driving force, the traction force and the abrasive resistance. And the front 
and rear of the wheels are equipped with two kinds of lights to light up the front road and warn passers-by.

The product rendering in Figure 7 was presented on the basis of the preliminary one by analyzing and comparing the strengths and weaknesses.
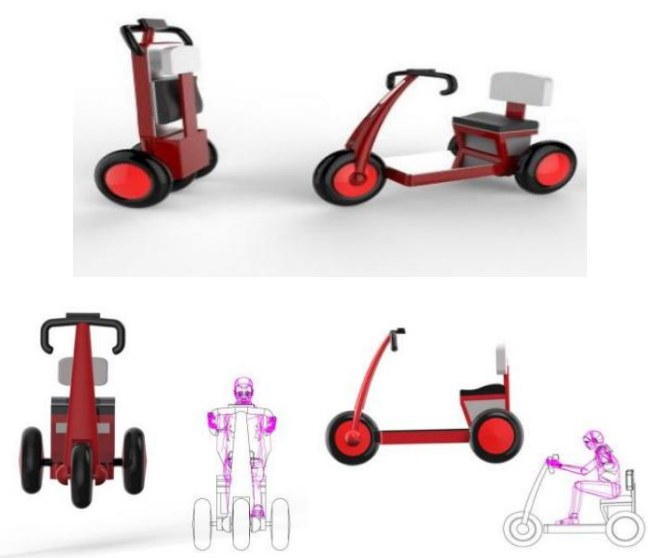

Figure 4. Design of lower limb mobility aids

Compared with the scheme sketch, the final scheme was adjusted in some details and retains the human body curve design of the seat to ensure comfort. An annular grip is designed for the handlebar, which makes the steering more flexible and smoother. The grip fits the contour of the human hand, and you can choose the straight grip and the side grip. The hand-held electromagnetic brake, which replaces grip brake and foot brake, becomes more convenient for the elderly. The annular grip, which is generally linked with the car frame, can support the elderly to get out of the car. The seatback is filled with silicone memory cotton to ensure sedentary comfort. The storage bag below the seat is made of synthetic spider silk polymer textile materials with high fiber strength so that it is uneasy to tear. The fabric plate inside the bag helps prevent deformation and is convenient and easy to fold. The damping wheel is made of PU foamed tire to totally get rid of flat tire risks. The tire adopts vertical and horizontal groove pattern combining the advantages of the straight and transverse groove patterns, with the characteristics of high stability, small rotation resistance, strong driving, braking and traction forces and strong drainage as well as slip \& abrasive resistance. The framework of the car body is made from the ABS polymeric structural material. The whole car can be folded, which facilitates carrying and storage. Based on the psychological implication of different colors, the appearance is designed in such colors as red \& yellow, green $\&$ blue, green $\&$ yellow, etc., which could pacify emotions and get rid of fatigue. The car body is equipped with the auxiliary devices like LED lights, warning taillights, etc. The GDP positioning device can locate the car position at any time by connecting with mobile phone map, so as to prevent the elderly from getting lost or losing the car.

\subsection{Product Performance Test}

To test whether the Product has practical effect on the elderly with partial disability of lower limbs, we selected a typical user for conducting comparison test between the Product and the traditional means of transport such as the multi-function wheelchair. The test above covers appearance design, ergonomics, operation procedure and use effect. Based on the travel distribution diagram of the elderly with partial disability of lower limbs, the respondents' feedback and experience effect of using the Product and multi-function wheelchair were tested by taking the communities, surrounding parks, squares, supermarkets, etc. all of which are within $3 \mathrm{~km}$ from the respondents' place of residence as destination based on the product experiment scale based on the IADL assessment standard; See Figure 3 for the results: Firstly, the elderly with partial disability of lower limbs are more likely to accept the product the appearance design of which could cater their psychological demands; secondly, the means of transport should satisfy the ergonomics principle and human's comfort needs and make up for the physiological defects of the elderly with partial disability of lower limbs; thirdly, the product should be operated as simply and conveniently as possible by the elderly which could use it independently. The product should also be easy to carry and store; fourthly, in terms of the using effect, the product can increase the travel distance of the elderly with partial disability of lower limbs effectively, shorten traveling time and improve the score of product experiment scale based on the IADL assessment standard so that the score can be within 2 to 3 points; it finally should influence the normal travelling of the elderly with partial disability of lower limbs and reach the ideal traveling effect with a 0 to 1 point.

Table3. Product test validation

\begin{tabular}{|c|c|c|}
\hline Comparison Test & $\begin{array}{l}\text { Means of Transport } \\
\text { for the Elderly with } \\
\text { Partial Disability of } \\
\text { Lower Limbs }\end{array}$ & $\begin{array}{l}\text { Traditional } \\
\text { Means of } \\
\text { Transport (the } \\
\text { Multi-function } \\
\text { Wheelchair) } \\
\end{array}$ \\
\hline Appearance design & $\begin{array}{c}\text { Smooth and } \\
\text { suitable } \\
\text { appearance; bright } \\
\text { and comfortable } \\
\text { color; }\end{array}$ & $\begin{array}{l}\text { Monotonous } \\
\text { appearance and } \\
\text { complex } \\
\text { structure; } \\
\text { gloomy color } \\
\text { and poor } \\
\text { affinity; }\end{array}$ \\
\hline Ergonomics & $\begin{array}{l}\text { The seat is } \\
\text { designed by } \\
\text { highlighting human } \\
\text { body curve to } \\
\text { ensure sedentary } \\
\text { comfort; the } \\
\text { annular grip is } \\
\text { convenient, labor } \\
\text { saving and fits } \\
\text { contours of the } \\
\text { human hands; the } \\
\text { handlebar support } \\
\text { could help the } \\
\text { elderly stand up; }\end{array}$ & $\begin{array}{l}\text { No standing } \\
\text { assistance part; } \\
\text { external } \\
\text { assistance } \\
\text { required for } \\
\text { sitting and } \\
\text { standing; }\end{array}$ \\
\hline Operation procedure & $\begin{array}{l}\text { The Product is } \\
\text { simple and easy to } \\
\text { operate, fold, carry } \\
\text { and store; }\end{array}$ & $\begin{array}{l}\text { Many parts } \\
\text { with complex } \\
\text { operation; } \\
\text { external } \\
\text { assistance } \\
\text { required; } \\
\text { uneasy to store } \\
\text { after folded; }\end{array}$ \\
\hline A.Riding & 1 point; user can & 3 points; \\
\hline
\end{tabular}




\begin{tabular}{|c|c|c|c|}
\hline \multirow[t]{6}{*}{ effects } & & take it alone; & $\begin{array}{l}\text { hardly carried } \\
\text { alone by user; }\end{array}$ \\
\hline & B.Shopping & $\begin{array}{l}1 \text { point; the Product } \\
\text { is light and can be } \\
\text { rode by user while } \\
\text { shopping; }\end{array}$ & $\begin{array}{l}2 \text { points; } \\
\text { other's care } \\
\text { required when } \\
\text { it is used; } \\
\end{array}$ \\
\hline & C. Travelling & $\begin{array}{l}0 \text { point: It can be } \\
\text { completed } \\
\text { normally; }\end{array}$ & $\begin{array}{c}1 \text { point; } \\
\text { completed with } \\
\text { difficulty } \\
\text { within a short } \\
\text { distance; }\end{array}$ \\
\hline & $\begin{array}{c}\text { D.Carrying } \\
\text { Heavy Objects }\end{array}$ & $\begin{array}{c}1 \text { point; the Product } \\
\text { is light and easy to } \\
\text { carry; }\end{array}$ & $\begin{array}{l}3 \text { points; too } \\
\text { large a volume; } \\
\text { others' } \\
\text { assistance } \\
\text { needed; } \\
\end{array}$ \\
\hline & $\begin{array}{c}\text { E.Arrangement } \\
\text { and Storage }\end{array}$ & $\begin{array}{l}0 \text { point; the folded } \\
\text { Product can be } \\
\text { pulled flexibly and } \\
\text { stored conveniently } \\
\text { and independently; }\end{array}$ & $\begin{array}{l}2 \text { points; } \\
\text { hardly stored } \\
\text { by user alone } \\
\text { after folding it; }\end{array}$ \\
\hline & $\begin{array}{l}\text { F.Stairs- } \\
\text { climbing }\end{array}$ & $\begin{array}{l}1 \text { point; the hand- } \\
\text { held handlebar of } \\
\text { folded product can } \\
\text { support the user go } \\
\text { upstairs; }\end{array}$ & $\begin{array}{c}3 \text { points; } \\
\text { hardly } \\
\text { completed } \\
\text { alone; other's } \\
\text { help needed; }\end{array}$ \\
\hline
\end{tabular}

\section{Conclusion}

Based on the developments of aging globally, this research targets the marginal group of the elderly with partial disability in their lower limbs, and conducts an innovative design practice for their short-distance travel. While researching, we investigated and analyzed the basic definition of the elderly with partial disability around the world, studied the social status of the elderly with partial disability in their lower limbs in China, conducted indepth communication with typical target groups, determined user needs, and drew portraits of the target groups. By analyzing ergonomics and product design principles and combining with an efficacy comparison for different materials, the final design and renderings were completed. Due to a lack of research on the elderly with partial disability in the industry, the links of data collection, collation, and induction in the research process are relatively weak, and the analysis of product structures and functionalities is still lacking in depth. This research, as a preliminary exploration for the elderly with partial disability in their lower limbs, hopes to provide a new design direction with the increasing aging population in China, and to provide some assistance to these elderly groups to revolutionize their travel experience and enjoy their golden years.

\section{References}

1. Du Xiaojiang, LIU Yongxiang. The Influence of the travel characteristics of the elderly on the design of travel-assisted products [J]. Industrial Design, 2020(10):63-64.
2. Hu Zenglin, WANG Huizi, GAO Hang, WANG Junjie. Co-word clustering analysis of hot spots in the study of disabled elderly in China from 2008 to 2017 [J]. Modern preventive medicine,2019,46(05):849-853.

3. Chen Jing. Research on the design of a mobility scooter for mildly disabled Elderly based on mental model [D]. China Academy of Fine Arts,2019.

4. Zhu Guowang. Analysis and Research on the elderly's travel and parking space use in the aging society [D]. Zhejiang Sci-Tech University,2020.

5. Jin shining. A study on the design of aging-assisted products based on behavioral needs [J]. Packaging engineering,2019,40(24):194-198+242.

6. Measurement of special access to home visit nursing services among Japanese disabled elderly people: using GIS and claim data[J].Takashi Naruse,Hiroshige Matsumoto,Mahiro FujisakiSakai,Satoko Nagata.BMC Health Services Research . 2017 (1)

7. Chen Haiyan, ZHANG Liping. Investigation and analysis on the current situation of osteoporosis knowledge among the elderly in the community and its influencing factors [J]. General Nursing,202,18(30):4188-4190.

8. Xu Zhongge. Ergonomics based design research on elderly mobility scooter [D]. Qingdao University,2020.

9. Dai Yiming. Research on the Design of Mobility Tools for the Elderly [D]. North China University of Technology,2018.

10. Liu Le, Zang Zhaoyan, LIU Jiantao, ZHANG Fangyu, WU Shuang, HE Yan. An analysis of activity ability, health self-assessment and depression in the elderly in China [J]. Med sci,2020,33(06):90-94.

11. Dai Shao. Research on the Design of Travel Tools for the Elderly based on user experience [J]. Industrial Design,2020(02):76-77.

12. Xiong Yangting. Application research of UCD design method in the design of walking AIDS for the elderly [J]. Packaging Engineering,202,41(10):342-344+348.

13. Liu Wei. Research on the design of a mobility scooter based on the social needs of urban elderly [D]. Shenyang Aerospace University,2019.

14. Shuo Fang Liu, Yang Zhang, Min Jiang. ANP-based analysis of design strategy, customer demand, and firm performance of the elderly motorized mobility scooter. 2018, 21:431-437.

15. Technology - Assistive Technology; Findings on Assistive Technology Discussed by Investigators at University of Twente (Value-based design for the elderly: An application in the field of mobility aids). 2017. 